\title{
Zona de colaboração: um modelo descentralizado de apropriação e replicação das tecnologias da informação e comunicação no MetaReciclagem
}

\section{Hernani Dimantas}

\section{Resumo:}

A apropriação da tecnologia social por meio do Meta:Reciclagem, um movimento de conversação que se iniciou na web em 2002, através de uma lista de discussão que debateu processos de inclusão digital no Brasil denominada de Metá:Fora. Apropriação de tecnologia social vigorando até os dias de hoje e intervindo na realidade social brasileira.

\section{Palavras Chave:}

tecnologia social; interfaces sociais da comunicação; apropriação; Metareciclagem; Metáfora

\begin{abstract}
:
This paper analyzes the use of social technology through Meta:Reciclagem, a dialogue movement that started in the web in 2002 in a discussion list - Metá:Fora - which focus digital inclusion processes in Brazil. It evaluates de use that has been made of social technology and its intervention in the Brazilian social reality.
\end{abstract}

\section{Keywords:}

social technology; social communication interfaces; appropriation; Metareciclagem; Metáfora

\section{Conceitos Iniciais de Inclusão Digital}

Ao final do século XX, mais especificamente na última década, começou a surgir no Brasil o debate sobre a importância do processo de Inclusão Digital, ecoando na sociedade civil organizada e governos.

Nessa época, os primeiros programas de governos e ONGs estabeleciam alguns conceitos de inclusão pela utilização das TICs (Tecnologias de Informação e Comunicação), como a oferta de banda larga, a partir de 2001, pelas companhias de telecomunicações por valores acessíveis a muitos internautas.

Somado a isso, ocorria, paralelamente, a disseminação da cultura hacker através da adoção de software livre em muitos projetos importantes, a exemplo dos Telecentros da Prefeitura do Município de São Paulo e do Acessa São Paulo (AcessaSP), do Governo do Estado de São Paulo, abrindo-se as condições para a emergência de projetos independentes na interface entre tecnologia e sociedade.

A população do Brasil está em torno de 200 milhões de pessoas. Somente $34 \%$ acessavam a Internet com frequiência (1). O gargalo da exclusão era enorme, tanto a exclusão social como a digital, segundo Sérgio Amadeu (SILVEIRA, 2004, p.33): "muitos dirigentes públicos e empresariais ainda acham que o uso do computador só é importante para a profissionalização da população. Essa visão (...) deixa de lado a dimensão da cidadania".

Não parece tão simples encarar esses problemas pelos métodos tradicionais. Inicialmente, as expectativas de 
colaboração ainda estavam num plano de articulação que se faz pelas vinculações da prefeitura, das ONGs e dos líderes comunitários. Não se pensava, todavia, na atuação daquelas pessoas interessadas no processo, ou seja, os verdadeiros atores. Tratava-se de um movimento de inclusão digital de cima pra baixo, fazendo com que o termo perdesse o seu significado inicial.

As iniciativas permeavam diferentes abordagens entre elas, a da indústria de tecnologia, a abordagem das ONGs, as iniciativas acadêmicas ligadas às universidades do país e a abordagem do poder público nas escolas. Entre as iniciativas, destacou-se uma abordagem colaborativa que teve sua inspiração em projetos de conhecimento livre, cujo expoente inicial foi o projeto GNU/Linux.

Software livre é a ponta do iceberg de um movimento para o conhecimento livre. A diversidade de vozes na internet, as multidões, ou pessoas trabalhando em rede têm um ritmo de produção e organização que as empresas tradicionais, grande parte da academia, o Estado e o terceiro setor também conseguem compreender.

Num ecossistema de idéias livres baseado na generosidade e no modo de produção catalisado pelo copyleft, a academia, as empresas, o Estado e o terceiro setor entram nessa equação, mas não como protagonistas ou como detentores do conhecimento e da inovação. São participantes, pois, neste ambiente hiperlinkado, a hierarquia é desbancada pela reputação.

No Brasil, esse é o diferencial apresentado pelos projetos independentes que, inseridos no movimento de inclusão digital, se caracterizaram por privilegiar a internet das pontas, assumindo uma posição inversa onde a periferia é o centro.

A colaboração pode ser entendida como um modo de produção que, diferente das idéias tradicionais, tem vida própria. Ela nasce em um ambiente caótico, como a internet, e emerge num movimento de baixo para cima, alcançando um nível razoável de organização.

\section{Zonas de Colaboração}

As pessoas têm na internet mais do que uma ferramenta. Utilizam-na como uma aliada. Dessa forma, catalisam a conversação entre pessoas comuns. E nesse ambiente de burburinho muitos projetos são desenvolvidos. Tais práticas se relacionam ao conceito de inteligência coletiva descrito por Howard Rheingold (2003), autor do excelente Smart Mobs, no qual diz que: "Toda vez que o poder descentraliza há oportunidades para a inovação. Como poderá essa nova descentralização fazer aparecer novas formas de ações coletivas?"

É exatamente na pergunta formulada por Rheingold que enxergamos as oportunidades de uma revolução em termos da apropriação das tecnologias pelas pessoas. Toni Negri e Michel Hardt (2004), em Multitude, denominam esse movimento transformativo de Multidão como o conceito de uma potência. "Essa potência não quer simplesmente se expandir, ela quer, sobretudo, conquistar um corpo: a carne da multidão quer se transformar no corpo da Inteligência Coletiva." Entendemos que o processo de redes catalisa a formação de coletivos. “(...) trabalho imaterial tende a tomar a forma social das redes baseadas na comunicação, na colaboração, e nos relacionamentos afetivos. O trabalho imaterial inventa as redes novas, redes independentes de cooperação pela qual a rede produz". (NEGRI; HARDT, 2004, p.66-67).

David Weinberger (2007), em Small pieces loosely joined, diz que o "conhecimento na Web é uma atividade social". A multidão transforma o corpo em inteligência coletiva que por sua vez retroalimenta, via conhecimento, as redes sociais. 
A Web é uma conversação, o oposto da mídia tradicional. Da maneira como aprendemos com McLuhan (1979), a natureza do meio tem conseqüências. Há uma tendência de as pessoas que habitam o ciberespaço, fazendo dele uma extensão da própria vida, encarar a internet como um novo lugar.

Conforme menciona Levine et.al. (2001), nesse lugar existem "pessoas conversando com pessoas". Embora a fronteira eletrônica extrapole a noção de lugar geográfico, o conceito de lugar, ou não-lugar, não é o que delimita as especificidades dessas vivências e experiências. Nelas o lugar é substituído por uma interface cultural que tem no link a expressão do inter-relacionamento de pessoas e grupos a partir de uma experiência distinta com o tempo e o espaço.

A atuação das pessoas em blogs, fotologs, Orkut ou em qualquer não-lugar informacional faz com que a voz, a comunicação não mais seja monopólio da mídia de massa, ou da idéia da comunicação de um para muitos. Entendemos que desde a revolução de Gutenberg a humanidade não apresentou algo tão original como a Internet para o rompimento do paradigma cultural efetivado pelo modernismo. A conversa de muitos para muitos tem um alcance espetacular na relação de poder. O poder, para Foucault (2005), provém de todas as partes, em cada relação entre um ponto e outro. Essas relações são dinâmicas, móveis, e mantêm ou destroem os esquemas de dominação.

A correlação de forças imanentes é expressa na rede como zonas de colaboração cujo conceito é o espaço informacional onde as pessoas comuns estão engajadas no desenvolvimento de comunidades, relações, nas conversações.

Cabe-nos pensar como essa problemática está sendo contemplada e como o estudo das teorias da comunicação podem desvelar o processo da formação de uma nova geração de comunicadores que, ao contrário das anteriores, se constituía de forma independente dos grandes meios de comunicação e tinha nas ferramentas de edição na internet, os blogs, seu meio de criação, difusão e troca de informação e conhecimento.

\section{O Conceito Metá:Fora e MetaReciclagem de Inclusão Digital}

Diante desse contexto, o objeto de estudo dessa pesquisa tem origem no trabalho do autor como participante do processo de desenvolvimento da cibercultura no Brasil, dando continuidade a uma pesquisa que se iniciou em 1999 com o desenvolvimento dos projetos Marketing Hacker, Metá:Fora e MetaReciclagem.

O primeiro deles, o Projeto Metá:Fora nasceu no campo da comunicação, já no âmbito de uma cultura digital brasileira, abordando o desenvolvimento dos blogs, na inter-relação entre essa ferramenta e a constituição de projetos colaborativos na realidade social de nosso país.

A internet é metáfora. Não no sentido comum da comparação, da figura de linguagem. Para Lakoff e Johnson (1980), em Metaphors we live by, a metáfora é transporte, um “entre": o sensório/subjetivo, juntos. De acordo com Fonseca (2004) o projeto Metá:Fora teve seu início em 2002, através de uma lista de discussão do YahooGroups, que reuniu, inicialmente, cento e cinqüenta pessoas, lusófonas, espalhadas pelo mundo, gerando uma série de projetos colaborativos e subprojetos, todos baseados no conhecimento livre.

Entretanto a origem do movimento, anteriormente à lista de discussão, se deu a partir da conversação e de idéias disseminadas no livro Marketing Hacker, de Dimantas (2003) e na Revista NovaE (2) e nas idéias de Felipe Fonseca no blog Hipercortex (3). Considerando que outras vozes começavam a se engajar num debate mais profundo sobre a apropriação tecnológica, colaboração e, via de regra, o ideal de transformação social poderia ser mais interessante se o debate fosse aberto para outras comunidades. 
Estávamos, naquele momento, presenciando uma nova experiência de publicação colaborativa na revista eletrônica NovaE, no entanto, a proposta inicial do projeto Metá:Fora era de ativar as inteligências coletivas através da colaboração distribuída e, basicamente, utilizando a internet como agente catalisador.

O Metá:Fora emergiu num plano rizomático, sob os moldes do conceito de rizoma, conforme Deluze e Guattari (2004). Essa emergência significa que foi construído sem uma hierarquia definida. As palavras, as discussões, foram mescladas num Wiki, ou seja, num espaço informacional onde juntávamos todas as elucubrações que surgiam desse embate colaborativo. Muitas pessoas participaram do projeto e deixaram seus nomes escritos: Felipe Fonseca, Daniel Pádua, Felipe Albertão, Dalton Martins, Glauco Paiva, Paulo Bicarato, Marcelo Estraviz, Paulo Colacino, Tupi, entre outros, trouxeram contribuições fantásticas para mixar os trabalhos de cada um visando a um objetivo maior e colaborativo.

E falar em conhecimento no ambiente rizomático tem a ver com conceitos como propriedade, liberdade e multiplicidade. Esses conceitos só podem ser colocados em prática por meio de uma autoria comum. Cabe dizer que esse modelo de conversação proposto foi replicado nas diversas áreas do conhecimento. É desse modo de agir que surge o conceito de tecnologia social, ou seja, o uso das ferramentas de comunicação através de uma apropriação colaborativa, conversacional e criadora de novos projetos.

Entretanto, não tendo como objetivo apenas o desenvolvimento cultural, ou mais especificamente, escrever livros, o movimento estava pronto para colocar em prática seus conceitos de emergência das vozes e o seu impacto na microfísica do poder, segundo Foucault (op.cit.). O Metá:Fora não pretendia utilizar o espaço informacional para um debate sem fim, sem meios e sem objetivos. Pelo contrário, desde o seu princípio carregou a ideologia do compartilhamento e da transformação social.

A importância do Metá:Fora está na migração da cultura hacker, que normalmente ocupa um espaço informacional no qual a referências à programação de computadores é o assunto dominante, para o âmbito do conhecimento.

O projeto tinha como alvo entender e desenvolver conhecimentos adequados a uma nova relação com a cultura interconectada, a partir de comunidades locais, para fomentar a inclusão digital e o uso efetivo de ferramentas de publicação pessoal e construção coletiva, ou como utilizar a tecnologia para incrementar a conversação na rede.

Em pouco mais de um ano, o Metá:Fora passou de uma lista de debates para um grupo de intervenção, utilizando conceitos de colaboração para desenvolver uma infra-estrutura ou incubadora, "chocadeira" de projetos colaborativos tornando reais a apropriação e a utilização das tecnologias para uma intervenção na realidade cultural brasileira.

Dessa forma, a transformação social pela apropriação tecnológica passou pelo questionamento daquilo que se chamava Inclusão Digital, passando pelo ativismo midiático, bem como, pela mistura cultural impulsionada e mediada pela cibercultura.

Num determinado momento percebemos, então, que o Metá:Fora era uma forma de troca de conhecimento. Percebemos que as pessoas conversavam com outras pessoas, imbuídas do mesmo interesse pela interatividade. Esse diálogo caótico e emergente nos possibilitou experimentar a transversalidade do aprendizado. Percebemos que na rede as pessoas aprendem, de fato, através da utilização das ferramentas colaborativas pelas próprias pessoas.

Os projetos desenvolvidos colaborativamente pelo Metá:Fora abrangeram desde soluções para acesso à internet até alternativas para estimular o espírito empreendedor das comunidades atendidas. Tais iniciativas 
estão baseadas em uma organização conceitual denominada Tríade da Informação, uma construção iniciada por Pierre Lévy (2001). Essa tríade era composta pelo meio físico, meio lógico e pela interatividade.

Ou melhor:

a) Infra-estrutura física: estações, servidores, dispositivos conectados à rede, integração de redes, estruturas alternativas de interconexão;

b) Infra-estrutura lógica: sistemas de publicação coletiva, adaptação a padrões de intercâmbio de informação;

c) Interação e integração de capital humano: as trocas de informação. Educação, arte e mobilização social.

Oriundo do Metá:Fora e concebido sob o mesmo conceito, o MetaReciclagem era um subprojeto que buscou tratar a reciclagem de equipamentos obsoletos com software livre, entregues a entidades de ação social, visando a utilização do computador como dispositivo em rede, com o objetivo primordial de integrar comunidades.

O MetaReciclagem estava dividido em duas ações concretas, uma em parceria com a ONG Agente Cidadão e outra em parceria com a Prefeitura de Santo André (Parque Digital). Esse projeto subsistiu ao fim do Metá:Fora, ganhou autonomia própria e hoje está inserido no projeto de inclusão digital do Governo de São Paulo, o AcessaSP.

O projeto Metareciclagem trabalhou, inicialmente, com o primeiro estrato da tríade da informação, a infraestrutura física. O objetivo era coletar, triar e reciclar microcomputadores usados e torná-los minimamente operacionais para a realização de operações básicas em projetos sociais: edição de textos, planilha de cálculo, acesso à web e troca de mensagens. Eventualmente eram utilizados microcomputadores com um perfil mais avançado para projetos que envolviam a produção, pelos usuários, de conteúdo multimídia.

Dois aspectos foram fundamentais no projeto MetaReciclagem:

- a utilização de software livre, por motivos econômicos, escalabilidade do software em relação ao equipamento na redução da dependência de fabricantes de software,

- a inversão do paradigma de "acesso" à tecnologia. Os equipamentos encaminhados pelo projeto não são simples terminais de acesso. São estações de produção colaborativa.

Uma gama de outros softwares livres orientados para a comunidade dos projetos também foram utilizados. Todos esses softwares trazem na bagagem o senso colaborativo, pois o software influencia a interação nas comunidades. Não só pelo lado da sustentação de um modo de produção colaborativo, mas pelo espelho virtual que o software livre reflete nas mentes das pessoas.

Isso não tem nada a ver com as máquinas. Máquinas apenas dão o suporte para a colaboração e interatividade. Computadores são apenas ferramentas que potencializam a conversação entre pessoas comuns. A dinâmica da informação não é uma equação balanceada. Hardware e software só podem ser entendidos em importância se estiverem servindo à integração da humanidade.

O MetaReciclagem apresentou, indiretamente, uma proposta para enfrentar o desafio da inclusão digital, pois contrariava a lógica da indústria da obsolescência (já que encontrávamos uma quantidade enorme de computadores usados e sucateados disponíveis no Brasil e, com a utilização de tecnologia compartilhada e livre, foi possível aumentar a vida útil desses computadores) e a reciclagem e a utilização de tecnologia livre, 
mais especificamente low-tech, possibilitam a diminuição dos espaços entre as comunidades ricas e pobres. A frase "periferia é o centro" exemplifica esse fluxo.

A periferia conhece muito mais sobre rede, mutirões, participação e mobilização. Creio que os esforços de inclusão devem ter como premissa que o conhecimento está na periferia, e que a produção local deverá passar pela inserção da tecnologia nos movimentos da comunidade. E para combater a miséria, a exclusão e o não exercício da cidadania temos que pensar em soluções criativas de integração das periferias com a tecnologia. Dar acesso à rede é importante, mas o mais consistente é criar condições para a circulação da informação.

A inclusão digital só será potencializada quando entendermos que as necessidades das pessoas não são as mesmas necessidades daqueles que concebem os projetos. Em primeiro lugar, vamos contextualizar as fases do MetaReciclagem como um processo de inclusão digital.

Podemos dividir em duas fases:

a) Fase 1: acesso ao computador.

b) Fase 2: acesso à informação.

Estas situações são bastante diferentes. A primeira fase pode ser resumida por uma pergunta: para que precisamos do computador? Empregabilidade pareceu ser uma resposta que atendia a todos os atores envolvidos. Ensinar computação ao povo necessariamente contribuiria para que os novatos rompessem com as fronteiras do trabalho. Essa idéia não se mostrou verdadeira.

Mas com o acesso à internet (e, por conseqüência, o acesso à informação) começou-se a perceber que as pessoas estão conversando com outras pessoas através da rede. Essa conversação traz na bagagem um novo incentivo cultural, catapulta as inteligências para novas instâncias. Assim, em vez de se orientar à empregabilidade, poderíamos disponibilizar ferramentas para a reverberação das vozes desses protagonistas. A retomada da voz é um atalho para a cidadania.

A experiência dos Telecentros da Prefeitura Municipal de São Paulo é muito interessante. Foi relevante pelo pioneirismo na utilização do software livre como plataforma de acesso à rede. O software livre significa, além da economia na aquisição de softwares e conseqüientemente a otimização dos recursos, a imersão num modo de produção colaborativo.

A terceira fase foi a circulação da informação dentro da comunidade conectada. Não podemos ignorar o conhecimento da multidão. É necessário, no entanto, que esse conhecimento seja tropicalizado. A junção desse conhecimento com as informações de fora da comunidade ativa o movimento cultural. Esta circulação tende a ser potencializada pela conversação entre as pessoas e intracomunidades, criando, assim, possibilidades infinitas de colaboração.

A originalidade da conversação que acontece no Brasil tem sua base na difusão do movimento de software livre, pela sua apropriação por diversas estruturas do governo, seja no âmbito federal, estadual ou municipal. E com forte aspecto ideológico e midiático.

Software livre aparece, nesse momento, como um agente catalisador do conhecimento livre. A história do conhecimento é a história de apropriações e reconstruções a partir das bases já existentes, ou seja, trata-se de adaptação às necessidades e/ou aos interesses de grupos e/ou comunidades.

Mas, para isso acontecer, demanda um engajamento das pessoas aos projetos. Esse engajamento não pode ser 
imposto. É um movimento que só acontece quando a comunidade sente necessidade no seu desenvolvimento. Um movimento de baixo para cima, de dentro para fora das comunidades. Esse processo espelha sobremaneira os anseios e necessidades das comunidades. E quando esta equação se torna balanceada, as comunidades têm a oportunidade de catalisar o próprio conhecimento que existe na comunidade. Esse conhecimento está impregnado nos mutirões.

As propostas atuais de inclusão digital sempre tocam num ponto muito similar: a criação de um telecentro, uma escola de informática ou uma sala de uso público onde as pessoas da comunidade local se dirigem para obter o acesso aos computadores e, onde os projetos estão mais evoluídos, o acesso à informação através da internet.

A partir disso, surgem várias propostas e formas diferenciadas para se validar esse acesso à informação. Desde a criação de blogs, sites colaborativos, listas de discussão, salas de bate-papo inter-telecentros e tantas outras formas de conectar pessoas, promover o debate entre elas. Embora as ferramentas de conversação estejam disponíveis na rede, os projetos de inclusão digital ainda não se deram conta do comportamento e necessidades das pessoas na rede. Embora isso seja apenas uma questão de tempo para que grupos organizados possam se apropriar do espaço informacional.

As mais variadas experiências pedagógicas modernas sempre levantam um tema de importância fundamental às suas metodologias de ensino: a experimentação e o aprendizado pelo erro com base nas necessidades latentes daquele que participa e constrói o processo educacional ao qual está inserido. Dessa forma, ter acesso aos recursos tecnológicos inerentes ao aprendizado de uma nova ferramenta no local onde a mesma participa do cotidiano de uma determinada tarefa é pedagogicamente um avanço e uma forma de efetivamente descentralizar o acesso e a experimentação desse novo processo técnico.

Portanto, por que não propor um projeto de inclusão digital que não se limite à criação de um telecentro público? Mas sim um processo de inserção da tecnologia em centros comunitários, pequenos grupos organizados, cooperativas, centros de encontro, entre outras formas de organizações sociais.

Se a periferia da rede passa a ser o centro no modelo onde os agentes produzem conhecimento e não apenas consomem dos grandes servidores do núcleo da rede, a evolução do conceito de inclusão digital como modelo de transferência de tecnologia e autonomia passa a ser a concretização do conceito de que a periferia, não apenas da rede, mas da sociedade, passa a ser o centro produtor das demandas de uma nova forma de enxergar a rede.

Em 2006, em minha dissertação de mestrado, abordei o tema da Linkania - a sociedade da colaboração. Na realidade, esse tema, embora amplo, tem o foco na nova condição dos atores para uma outra modalidade, onde a participação pública deixa de ser transcendental e passa a coexistir, juntamente com outras pessoas em rede, num plano de imanência.

Uma nova sociedade colaborativa emerge no caos. Essa sociedade está baseada numa forma de organização muito bem exemplificada por Eric Raymond (1998) no ensaio The Cathedral and the Bazaar, onde o autor faz uma análise tendo como objeto o desenvolvimento de um software denominado Fetchmail.

Dessa forma, esse projeto pretende a refazer o percurso de Eric Raymond no âmbito do conhecimento livre. Da mesma forma que buscamos um modelo de desenvolvimento de software sob um aspecto de colaboração, de liberdade, de apropriação e replicação pensamos na necessidade de pesquisarmos um modelo de produção colaborativa. Principalmente, com foco em projetos de inclusão digital e de projetos colaborativos advindos da utilização da internet como rede potencializadora. 
Os espaços informacionais contemplam comunidades, softwares sociais, ferramentas de conversação e comunicação. Esses espaços são catalisados por uma conversação assíncrona que emerge na rede ao ponto de provocar rupturas na cultura de massa.

Uma cultura de rede traz a reboque uma nova forma de organização descentralizada, tanto do ponto de vista da organização per si como da comunicação mediada pela tecnologia hiperconectada. Essa cultura de rede se expande rapidamente. Pessoas comuns se apropriam dessas tecnologias e reverberam em suas comunidades aquilo que aprenderam. A replicação é a forma pela qual as pessoas se valem para aprender e ensinar nesse novo paradigma informacional.

As tecnologias da informação e comunicação são o cenário lógico para a expansão das zonas de colaboração como um meio de produção no contexto da formação de uma nova geração de comunicadores que, ao contrário das anteriores, se constituí de forma independente dos grandes meios de comunicação e tem nas ferramentas de edição na internet, os $b \log s$, seu meio de criação, difusão e troca de informação e conhecimento.

\section{Bibliografia:}

DELEUZE, G.; GUATTARI, F. Mil Platôs: capitalismo e esquizofrenia. São Paulo: Editora 34, 2004. v. 1.

DIMANTAS, H. Marketing Hacker: a revolução dos mercados. Rio de Janeiro: Garamond, 2003.

Linkania: a sociedade da colaboração. 2006. 77 f. Dissertação (Mestrado em Comunicação e Semiótica) - Pontifícia Universidade Católica de São Paulo, São Paulo, 2006.

FONSECA, F. Tecnologia social. São Paulo, 2004. Disponível em: < http://portal.softwarelivre.org/news/2010> Acesso em: 28 fev. 2006.

FOUCAULT, M. Microfísica do poder. 21.ed. Rio de Janeiro: Graal, 2005.

LACKOFF, G. JOHNSON, M. Metaphors we live by. Chicago: University Chicago Press, 1980.

LEVINE, R. et. al. The cluetrain manifesto: the end of business as usual. New York: Basic Books, 2001.

LÉVY, P. A conexão planetária: o mercado, o ciberespaço, a consciência. São Paulo: Editora 34, 2001.

McLUHAN, M. Os meios de comunicação como extensões do homem (understanding media). São Paulo: Cultrix, 1979.

NEGRI, Toni; HARDT, Michael. Multitude: war and democracy in the age of empire. New York: The Penguin Press, 2004.

RAYMOND, Erick. A catedral e o bazar. Trad. Erik Kohler. 1998. Disponível em < http://www.geocities.com/CollegePark/Union/3590/pt-cathedral-bazaar.html> Acesso em 11 jul. 2008.

RHEINGOLD, H. Smart mobs: the next social revolution. New York: Perseus Books, 2003.

SILVEIRA, S. A. et. al. Software livre e inclusão digital. São Paulo: Conrad, 2003.

WEINBERGER, David. Small pieces loosely joined: a unified theory of the web. New York: Perseus 
Books, 2002.

\section{Notas:}

(1) Fonte: CGI.BR: Comitê Gestor da Internet no Brasil: Pesquisa sobre o uso das Tecnologias da Informação e da Comunicação no Brasil, 2007.

(2) Disponível em: http://www.novae.inf.br/site/modules.php?name=Conteudo\&pid=605 Acesso em 17 jul. 2008.

(3) Disponível em: < http://felipe.hipercortex.com/> Acesso em 17 jul. 2008.

\section{Mini Currículo :}

Hernani Dimantas é graduado em Agronomia pela Universidade de São Paulo (1983). Mestre em Comunicação e Semiótica pela Pontifícia Universidade Católica de São Paulo. Atualmente é coordenador de conteúdo do Programa AcessaSP - Governo do Estado de São Paulo, Coordenador do LIDEC - Laboratório de Inclusão Digital e Educação Comunitária - Escola do Futuro - USP. Articulador do projeto Metareciclagem. 